“Rough! Tough! Real Stuff!": Music, Militarism, and Masculinity in American College Football

Author(s): John Michael McCluskey

Source: American Music, Vol. 37, No. 1 (Spring 2019), pp. 29-57

Published by: University of Illinois Press

Stable URL: https://www.jstor.org/stable/10.5406/americanmusic.37.1.0029

JSTOR is a not-for-profit service that helps scholars, researchers, and students discover, use, and build upon a wide range of content in a trusted digital archive. We use information technology and tools to increase productivity and facilitate new forms of scholarship. For more information about JSTOR, please contact support@jstor.org.

Your use of the JSTOR archive indicates your acceptance of the Terms \& Conditions of Use, available at https://about.jstor.org/terms 


\title{
"Rough! Tough! Real Stuff!": Music, Militarism, and Masculinity in American College Football
}

\author{
Hullabaloo, Caneck! Caneck! \\ Hullabaloo, Caneck! Caneck! \\ Good-bye to Texas University, \\ So long to the orange and the white \\ Good luck to the dear old Texas Aggies \\ They are the boys that show the real old fight \\ "The Eyes of Texas Are Upon You," \\ That is the song they sing so well,- \\ So Good-bye to Texas University, \\ We're going to beat you all to - \\ Chig-gar-roo-gar-rem! \\ Chig-gar-roo-gar-rem! \\ Rough! Tough! Real Stuff! Texas AEM. \\ -James Vernon Wilson's lyrics to "The Aggie War Hymn" (1918)
}

In 1918 a Texas A\&M University (A\&M) student named James Vernon Wilson was stationed in Germany as part of the United States' operations during the First World War. While on guard duty along the Rhine River, he penned a set of lyrics centered on the rivalry between his alma mater and the Longhorns of the University of Texas at Austin (UT). ${ }^{1}$ Following the war, Wilson returned to campus with the lyrics in tow

John Michael McCluskey is an assistant professor of music at Shorter University in Rome, Georgia, as well as the chair of the Department of Music. His broad interests center on music as a facilitator of social experience, whether in concert halls, clubs, worship spaces, living rooms, or stadiums. He holds his PhD in musicology and ethnomusicology from the University of Kentucky, where he completed his dissertation on music in college football. He is currently serving as the layout editor for the Society for American Music's Bulletin, and his writing has appeared in the Journal of the Society for American Music. 
and performed the song several times with a quartet of A\&M students. During this time, Wilson's song was known by a few different names, including "The Battle Hymn of A. \& M." and "Good-Bye to Texas University." The latter was the title of the song's initial copyright in 1921, along with the subtitle "The Aggie War Hymn," which would eventually become the name most associated with the tune. ${ }^{2}$

Wilson's original verse contains a total of thirteen lines. Of these, five either directly reference UT or describe the school by association. In these lines, Wilson rejects both the colors associated with the rival institution and its fight song, "The Eyes of Texas." 3 Customarily, when A\&M supporters-referred to as "Aggies" in the song-sing the line that shares its text with UT's fight song, the audience members shout "sounds like hell" before continuing on to the next line, contributing an additional insult to the phrase "The Eyes of Texas."4 Four of "The War Hymn's" lines extol A\&M, but only by comparison to the Longhorns. The first instance of this occurs as Wilson wishes the Aggies "good luck" before stating that they "are the boys that show the real old fight." Because of this phrase's position in between two explicit references to the Longhorns, one understands that the Aggies "show the real old fight" in contrast to the players from UT. This message is reiterated in the song's final line, "Rough! Tough! Real Stuff!" Wilson's use of the word "real" in both lines signifies the Aggies as being bona fide, possessing the moral and athletic aptitude that constitutes the masculine values the song espouses while maintaining that the Longhorns lack such characteristics. Furthermore, the song's only first-person-plural pronoun occurs toward the end of the verse, with "we're" shifting the song's perspective from that of an outsider commenting on a heated rivalry to that of an Aggie full of institutional bias. This transformation culminates with the line, "We're going to beat you all to [hell]."5 The lyrics' other four lines consist of nonsense syllables taken from two already extant Aggie "yells" (phrases chanted in unison by a crowd, effectively identical to cheers), "Hullabaloo, Caneck! Caneck!" and "Chig-gar-roo-gar-rem!" These chants, alongside many others, originated at A\&M in the early twentieth century as a practice in the school's Corps of Cadets, a student military organization. At football games, cadet leaders guided students through yells in the stands. They also led these cheers during the pregame period and at halftime, when the entire corps formed a mass block " $\mathrm{T}$ " formation on the field. John A. Adams describes the practice as initially being a form of "crowd control" that eventually became "a major force to direct the 'old pep' of the students." 6

While most college football programs are not as clearly connected to militarism as the Aggies, martial associations are central components to college football culture. Discourses associated with war are one of the primary means by which football's violence is valorized as a crucial 
"man-building" activity. Football has been connected to martial music since the sport's emergence in the years immediately following the American Civil War. From the first intercollegiate game between Rutgers and Princeton on November 6, 1869, American football has been a battle for territory between opposing forces, with various rules and specializations dictating how each side may engage with the other. The wind bands of college football's soundscape allude to how intertwined football and militarism are, as many collegiate football marching bands are descendants of military-affiliated musical ensembles that were established on college campuses across the United States shortly after the Civil War. ${ }^{7}$ As football grew in popularity, its militaristic qualities were championed as instilling participants with core American values. During World War II, General George C. Marshall (1880-1959), then the US Army chief of staff, gave the following order, "I want an officer for a secret and dangerous mission. I want a West Point football player." ${ }^{1}$ Years later, at a coach-of-the-year dinner in 1960, Robert Kennedy (1925-68) proclaimed, "Except for war, there is nothing in American life which trains a boy better for life than football." 9 Similar sentiments earned his brother, President John F. Kennedy (1917-63), a place hosting the coach-of-the-year award ceremony for the National Football Foundation in 1961. The organization cited his "believing firmly in the important role played by amateur athletics in the development of leadership qualities and moral values in American youth" as his primary qualification, further connecting American "moral values" with militarism. ${ }^{10}$ This statement reflects what Ken McLeod describes as a "warrior ethos" that "reinforced the pressure on American males to live up to a masculine heroic ideal of the "fight."'11

Such associations with militarism prompt consideration of the very title of A\&M's "Aggie War Hymn," which associates football with battle and battle with religious worship. There is not much to speak of musically that justifies the presence of the word "hymn" in the song's title. The lyrics themselves make no mention of spiritual matters, and the music is hardly reminiscent of hymnody, moving at a march tempo, with spectators singing in unison rather than in harmony. It is more likely that the term "hymn" signifies that the song's content can be read as doctrine for A\&M supporters. Aggies function as a cultural group united by rituals that hold near-religious significance for its members. Their creed is stated in their hymn, and their gatherings - the games - are moments of sacred importance that position individuals within a congregation of like-minded persons, communicate cultural values, and are crucial components of the process of societal indoctrination. To this "religious" body, wars - both in the metaphorical games being played on the field and in the literal military practices with which A\&M has long-standing connections-provide the opportunity to develop the idealized, even mythological, masculine qualities possessed by the athletic heroes representing 
their institution. A true Aggie is described as "Rough!" and "Tough!," as "show[ing] the real old fight," and, presumably, as being capable of beating any UT representative "to hell." In each instance, masculine value is based upon one's physical abilities and endurance. One must have grit to be an Aggie, as Aggies possess grit of a larger quantity and more conservative purity ("real old") than that of their opponents. Indeed, the song's cases of emphasizing the "realness" of an Aggie's "stuff" or "old fight" can be read as a sort of religious obsession with purity, searching for a sort of authentic masculinity: a testosterone-driven manliness that is burly and ready to kick some ass.

This article explores music's role in the enculturation of this brand of masculinity within college football soundscapes, drawing on film and communication theory to form a critical lens for reading fieldwork I conducted over the 2013 college football season. During this time frame, I traveled to sixteen institutions (see table 1) in the Football Bowl Subdivision of the National Collegiate Athletic Association (NCAA), researching the narrative function of music within college football stadiums. The universities represented in this study span locations from Florida to Oregon, and each institution is a member of the five largest and wealthiest conglomerates of university athletic departments, known as the "Power Five," including the Atlantic Coast Conference (ACC), the Big 10, the

Table 1. Institutions Included in 2013 Research Sample

\begin{tabular}{llll}
\hline Date & City & Home institution & Conference \\
\hline August 31 & Atlanta, GA & $\begin{array}{l}\text { Georgia Institute of Technology } \\
(\text { GT) }\end{array}$ & ACC \\
September 7 & Miami, FL & University of Miami (Miami) & ACC \\
September 14 & Tallahassee, FL & Florida State University (FSU) & ACC \\
September 21 & Columbus, OH & Ohio State University (OSU) & Big 10 \\
September 28 & Morgantown, WV & West Virginia University (WVU) & Big 12 \\
October 5 & Ann Arbor, MI & University of Michigan (MICH) & Big 10 \\
October 10 & Los Angeles, CA & University of Southern California & Pac 12 \\
& & (USC) & Pac 12 \\
October 12 & Pasadena, CA & University of California at Los & Angeles (UCLA) \\
October 19 & Stanford, CA & Stanford University (STAN) & Pac 12 \\
October 26 & Eugene, OR & University of Oregon (UO) & Pac 12 \\
November 2 & Bloomington, IN & Indiana University (IU) & Big 10 \\
November 7 & Waco, TX & Baylor University (BU) & Big 12 \\
November 9 & College Station, TX & Texas A\&M University (A\&M) & SEC \\
November 16 & Austin, TX & University of Texas at Austin (UT) & Big 12 \\
November 23 & West Lafayette, IN & Purdue University (PUR) & Big 10 \\
November 30 & Lexington, KY & University of Kentucky (UK) & SEC \\
\hline & & & \\
\hline
\end{tabular}


Big 12, the Pacific 12 (Pac 12), and the Southeastern Conference (SEC). I attended a game at each of these institutions, collecting and recording information about the musical practices in college football stadiums. I also interviewed individual agents who impact the soundscape of their respective stadiums, such as a member of the marching band staff and/ or a representative of the athletic department's production team. By critically reading the total body of this fieldwork through the lens established below, I map the soundscape of a college football stadium-including music played by the band and over the public address system, as well as cheers-onto a linear progression of militarized masculinity shared between both film and football contexts in which the male form is glamorized, subjected to violent physical trials, and then glorified as a result of those trials.

\section{Staging Masculinity}

In Paul Smith's analysis of Clint Eastwood's portrayals of masculinity in film, Smith theorizes that displays of men possessing qualities such as those espoused by "The Aggie War Hymn" and shared by Eastwood's famous tough-guy roles provide pleasure to viewers / spectators in three consequent stages, acting as a sort of mythological hero archetype. ${ }^{12}$ In the first, men are appreciated for their form as it exists in its context, whether stationary or in motion, against landscapes or in urban environments. This stage is always followed by the second, "the destruction of that body. That is[,] the heroic man is always physically beaten, injured, and brought to breaking point." The third stage follows, which "provides the security and comfort of closure, and is a crucial element in the production of spectatorial pleasure," allowing the hero "to emerge triumphant within the movie's narrative line." Smith summarizes these stages as a "three-stage shift from objectification to masochism to empowerment," noting that the process allows for "the conservation of norms of male sexuality within the discourses of popular culture."13 Given the important role of sports, and of contact sports in particular, in the enculturation and preservation of similar constructions of masculinity, it is useful to consider how Smith's process transfers to sporting contexts, particularly to contact sports such as football, hockey, boxing, and rugby. Additionally, Smith relies largely on cinematography analysis in his study, but the musical element of mediated entertainment also serves an important function in this process, as is demonstrated below by applying Smith's theory to this study's fieldwork.

In the case of college football, music serves as one of the primary signifiers as the athletes move through Smith's three stages. The first involves the introduction of the players to the field of play, whether in warm-up periods or, as occurs in many sports, as they are individually introduced 
over the public-address (PA) systems. In this stage, musical selections reflect institutional or individual accomplishments. The second period consumes most of the event's time frame, as athletes struggle against their opposition, facing physical trials as they seek to find victory. This is the primary space in which martial sonic signifiers are used to associate the trials of the players with those of battle. When injuries occur in this section, play stops to allow injured players to receive medical attention and be helped off the field of play, occasionally to be taken directly to a hospital for treatment. Typically, during these moments all musical activity ceases, separating these instances of vivid reality from the rest of the pageantry-saturated event. Surrogate players quickly replace these individuals, and the game's physical trials continue toward their conclusion. The third stage, in which the hero "emerges triumphant," occurs in two distinct but not mutually exclusive ways. The first and most obvious method is by winning the contest, succeeding in the quest to dominate physically one's opponent. The second is by achieving some deeper level of personal understanding through the trial. Frequently, sports commentators will refer to teams who played well but still lost as achieving a "moral victory." This phrase highlights the supposed inherent value of these masculine trials: even in losses, players learn life lessons regarding teamwork, overcoming adversity, and pushing beyond perceived limitations. To blend the sports and film applications of this theory together, consider the message of Rocky (1976), a movie in which a male boxer achieves peak physical condition through grueling training, faces the ultimate trial in his climactic match, and loses, but he understands more about himself, his family, and his career through his ordeal. These lessons provide a sense of "triumph" despite his athletic defeat. In college football, these moments are musically celebrated with the performance of institution-specific selections that celebrate the accomplishments of the team and its history.

In this context, the physical trials that take place between athletes in college football act as moral lessons. Players are broken so that they may emerge as warriors. Additionally, college football's process of struggle acts as a crucial component in yielding the "Rough! Tough! Real Stuff!" that is championed by the sport's culture as being intrinsic to Americanness. Similarly, Sue Curry Jansen posited the term "warspeak" as a means of referring to the use of martial language in sporting contexts during the Persian Gulf War in her consideration of the role of language in perpetuating associations between militarism and sport. Examples of warspeak in football include commentators describing players as "fighting and dying" or being "on the front lines."14 Jansen extends the Gulf War's scope to the 1991 Super Bowl (XXV) in Tampa, Florida, between the Buffalo Bills and the New York Giants, which was staged as a war spectacle 
involving a barricaded stadium, X-ray security searches of 72,500 fans, antiterrorist squadrons in the stands, hand-waving-size American flags distributed to every seat, a rousing rendition of the national anthem by Whitney Houston, and a halftime speech by President George H. W. Bush. The drama was heightened by the probability of interruptions of the game coverage for news bulletins about new Scud missile attacks on Israel or Saudi Arabia or other combat action. ${ }^{15}$

This article extends Jansen's concept of warspeak to "warsound" as a means of considering the sonic environment of a football game as it pertains to the narrative of physical trial as masculine trait. For these purposes, this article divides warsound into two categories of signifiers: sounds directly representative of the military tradition and musical selections connected with militarism through cinematic associations. These are not comprehensive possibilities but rather lenses through which one may consider the density of the network connecting college football, militarism, and masculinity. Additionally, any stage of Smith's "Eastwood Bound" progression may draw upon one or both categories of warsound, as is reflected in the stage-based discussions below.

This article applies the framework of Smith's Eastwood-inspired stages of masculinity — which this article refers to as "Rough!," "Tough!," and "Real Stuff!"- to college football's soundscape. Coupled with Jansen's conceptualization of war-adjacent discourses that manifest in sport, these case studies and interviews demonstrate that this American pastime's soundscape portrays masculinity as an inherently militarized expression dependent on violence as a form of cultural capital.

\section{"Rough!"- the Ideal Male Form}

In Smith's first stage of masculine progression, spectators gaze upon and appreciate the male form as it operates in an ideal, unbroken state. In college football stadiums, this stage occurs during the pregame period, in which players take the field to warm up, stretch, and perform practice drills. ${ }^{16}$ As players move through these activities some wear only a variation of their full uniform, perhaps without their pads or helmet, as they do noncontact stretches or exercises. Others wear their complete armor, including helmets and pads protecting their heads, knees, and shoulders, as they perform contact drills. This period also marks the first opportunity for audience members to enter the stadium and take their seats, designating this space as the first in which the roles between spectators (those in the stands) and spectacles (those on the field) are clearly defined. Here athletes' bodies are at center stage as they are primed and prepared for the trials that will follow. During the pregame period, music serves both as an entertaining accompaniment and as a functional tool. 
Table 2. Popular Music Selections Used in Player Warm-Ups

\begin{tabular}{llll}
\hline Institution & Selection & Performer & Genre \\
\hline OSU & "Go Off" (2012) & KB & Rap \\
OSU & "Momentum" (2012) & Stevie Stone & Rap \\
WVU & "Turn Up" (2012) & Gent \& Jawns & Rap \\
MICH & "Started from the Bottom" (2013) & Drake & Rap \\
MICH & "Swag Surfin"" (2009) & F.L.Y. (Fast Life & Rap \\
& & Youngsters) & \\
MICH & "All the Way Turnt Up" (2010) & Roscoe Dash & Rap \\
MICH & "I Don't Want to Stop" (2007) & Ozzy Osbourne & Metal \\
MICH & "Let's Go" (2004) & Lil Jon & Rap \\
MICH & "We Still in This, Bitch" (2013) & B.o.B. & Rap \\
MICH & "We Own It" (2013) & 2 Chainz & Rap \\
MICH & "Remember the Name" (2005) & Fort Minor & Rap \\
UO & "Public Service Announcement" (2003) & Jay Z & Rap \\
UO & "Stronger" (2007) & Kanye West & Rap \\
UO & "Get Lucky" (2013) & Daft Punk & Pop \\
UO & "Joker and the Thief" (2005) & Wolfmother & Metal \\
UO & "Blow Up" (2010) & J. Cole & Rap \\
IU & "Heart of a Champion" (2004) & Nelly & Rap \\
IU & "Throw It Up" (2002) & Lil Jon \& the East & Rap \\
& & Side Boyz & \\
A\&M & "You Don't Want These Problems" & DJ Khaled & Rap \\
A\&M & (2013) & & \\
A\&M & "Bose My Gind" (2013) & Young Jeezy & Rap \\
A\&M & "4 What" (2013) & Project Pat & Rap \\
UT & "I'm a Coke Boy" (2013) & DJ Drama & Rap \\
UT & "Ball" (2012) & Chinx Drugz & Rap \\
\hline
\end{tabular}

Table 2 outlines each of the selections encountered in this study during player warm-up periods across seven universities.

\section{Time-Out: A Case Study in Pregame Programming}

To elaborate on one set of warm-up selections, on October 26, 2013, at the University of Oregon (UO), players were guided from one warmup activity to another by musical selections played over the stadium's PA system. Megan Robertson, UO's director of promotions and gameday experience, explained that this music is chosen by the athletes and coaching staff, calling it "the players' mix ... what the players want to hear," including music that "helps get them in the right mindset." 17 These pregame selections included Jay Z's "Public Service Announcement" (2012), Kanye West's “Stronger" (2007), Daft Punk's “Get Lucky” (2013), 
Wolfmother's "Joker and the Thief" (2005), and J. Cole's "Blow Up" (2010). Robertson indicated that at UO the pregame warm-up selections are specified by the coaching staff, while the production crew chooses the other musical selections amplified throughout the stadium during the remainder of the gameday activities. Robertson described the ideal pregame ambience at UO as "intensity": "The music that is played every game for the team is the rap, is the rock, is the intense, fire-it-up" brand of popular music that inspires players to "hit them hard, score early, score often." 18

The pregame musical selections at UO not only designate timing to the athletes but also project additional messages onto the players. In "Public Service Announcement," Jay Z, a rapper, makes several claims regarding greatness that transfer to the athletes. The song opens with a voice-over that states, "I present this recording as a living testament and recollection of history in the makin' durin' our generation." This message signifies that these athletes' performances are of historic proportion. In the song's final verse, Jay Z explicitly likens his own personality to that of an athlete: "Check out my swag yo, I walk like a ballplayer." With this selection musical agents encourage audiences to admire the way these athletes carry themselves and how their movement is distinct from an average person's. "Stronger," a rap selection by Kanye West, repeats the message "that don't kill me can only make me stronger," which can be read as alluding to the athletes' upcoming physical trials. The song's opening lines, "Work it, make it, do it / Makes us harder, better, faster, stronger," encourage the athletes to improve their physique while indicating to audiences the hardness, speed, and strength of the athletes' "better" bodies. ${ }^{19}$ Following this, "Get Lucky" by Daft Punk, an electronic popular music duo, signaled the next round of activities from the athletes on the field. This song includes the refrain "We've come too far to give up who we are / So let's raise the bar and our cups to the stars." During this pregame period, phrases like "we've come too far to give up" and "let's raise the bar" celebrate the body of work the athletes have accomplished already and compel them to continue to exceed previous performance expectations. The song's frequently repeated hook, "We're up all night to get lucky," can be read as expressing the audience's joy at watching the athletes compete in this game or perhaps as an allusion to "scoring," as the term connects sports to sexual conquest. A brief looped groove followed this selection and signaled that another group of players was joining those already warming up. Once these new athletes arrived at their position on the field, Wolfmother's "Joker and the Thief" prompted the players to begin their next set of activities. This heavy metal selection is full of distorted guitars playing virtuosic solos featuring fast arpeggios and lyrics describing mythological figures who are "always laughing in the midst of power / Always living in the final hour."20 Finally, the 
rap artist J. Cole's "Blow Up" marked the final exercise for the players. This song is replete with references to physical power and destroying adversaries. This reading is bolstered by the song's opening lines ("This is a song for my haters / Y'all got me feeling like the greatest"), which cite adversity as a means of self-improvement. After establishing this premise, Cole introduces the song's primary refrain: "I'm about to blow up / I came up, I warmed up, the next up / I'm about to blow up." 21 That this selection sounds during UO's "warm-up" period is significant: "Blow Up" references a period of preparation preceding the subsequent physical contest between opponents. This selection was the final track that sounded before UO players vacated the field to conduct their final pregame preparations.

The selections described above span a variety of genres, including rap, heavy metal, and electronic popular music. While these selections are disparate in their instrumentation, grooves, and lyrical focus, they are all upbeat selections by male performers that reinforce a construction of masculinity rooted in power and either violent strength or sexual conquest, qualities shared by the vast majority of the music played over stadium amplification that I encountered in my fieldwork. Furthermore, Ken McLeod has explored the connection between African American athletic performances and violent-themed rap, the genre that most dominates the pregame section described above. McLeod explains, "Violent and rough play [in sport] often gets more television airtime than normal play, just as rap music generally reaches mainstream headlines when there has been some type of violent or criminal behavior," leading to the perception that "overt aggression and violence ... [are] acceptable means to achieve upward mobility." 22 Pregame musical programming such as that found at UO further reinforces McLeod's reading, reinforcing stereotypes associating black masculinity with violence. ${ }^{23}$

\section{Time-In: Resuming “Rough!”—the Ideal Male Form}

All the additional selections listed in table 2 lend themselves to readings such as the one above. By the conclusion of the players' warm-up period the audience members have encountered numerous sonic signals prompting their appreciation of the athletes' physiques and the power and potential that their figures represent. After the athletes vacate the field following warm-ups, another portion of the pregame stage begins, centered on the field show performed by the marching band.

The music featured during the field show is largely centered on two themes: nationalism and celebration of the hosting institution. Regarding the former, this period includes a moment of paninstitutional solidarity as the national anthem-and occasionally other patriotic selections-is performed by the marching band or a guest artist. This performance is 
followed frequently by a moment of silence or an invocation. Typically, this patriotic moment is accompanied by some amount of martial imagery, such as the presentation of the American flag by members of the armed forces. Given the long-standing military band tradition, a wind band's performance of the national anthem in this context reads as an example of warsound. Occasionally, this sonic environment is bolstered by troops parachuting into the stadium and/or by fighter jet or helicopter flyovers. Charles Garrett went so far as to describe the spectacle of the National Football League's (NFL) championship game, the Super Bowl - which typically includes more of these signifiers than not-as a form of "nation-building" capable of projecting cultural imperialism at both the national and global levels. ${ }^{24}$

Pregame is also the stage at which marching bands introduce their university's school-specific songs, such as a fight song or alma mater, as they create various formations on the field, such as an outline of the hosting institution's state or by scripting the university's initials on the field. Typically, the marching band members, in pseudomilitaristic uniforms, form a path for the football players to reenter the field for the contest as the musicians perform the university's fight song, which celebrates the school's athletic accomplishments. At UO the band's pregame performance concludes with "Mighty Oregon," which describes the school's athletes as "warriors" who dominate their opponents by "plough[ing] through the foeman's line":

Oregon, our Alma Mater, we will guard thee on and on.

Fellows gather 'round and cheer her; chant her glory, Oregon.

Roar the praises of her warriors, sing the story, Oregon;

On to victory urge the heroes of our Mighty Oregon.

We will march, march, on down the field, fighting for Oregon.

Plough through the foeman's line their strength we'll defy.

We'll give a long cheer for our men. We're out to win again.

OSU [Oregon State University] may fight to the end but we will win. $^{25}$

Following this performance, the football team takes the field, led by the university's mascot, Donald Duck, who is donned in the university's colors and who rides into the stadium upon a thoroughly masculine symbol of American culture: a Harley-Davidson motorcycle.

Some variation of the pageantry described above occurred before each of the games included in my research, and this pregame ceremony is a standard component of the sport's pageantry. As athletes prepare on the field, music reinforces the strength and capability of their bodies and invites audiences to appreciate the power that their bodies possess. As the pregame stage concludes, the marching band reinforces this message while alluding to the coming contest, the stage in which players' 
bodies are tested against the strength of the opposing team. Much like the audiences for Eastwood's western films, football's spectators reach the conclusion of the first stage with an appreciation for the heroic male form and its capabilities but recognize that their heroes are about to face a period of difficulty and trial in which these bodies will be tested and potentially broken.

\section{“Tough!"-Building Masculinity through Trial}

The second stage by which masculinity is communicated in college football-Smith's stage of trial-consumes most of the time during which these events unfold. The use of warsound is paramount in this portion of the game: audiences are reminded of the value of football's violence as they watch athletes struggle against each other while the game progresses. One of the most glaring examples of warsound in college football is the frequent presence of sirens in stadiums as a means of associating passing-centric offenses with wartime aerial assaults. Of this study's sixteen case studies, four universities incorporated air-raid sirens to represent either their offensive strategy or specific types of passing plays, including WVU, IU, A\&M, and UK. ${ }^{26}$ An athletics production staff member for WVU (this study refers to him as "Richard") explained that the school implemented this specific sound effect in 2012: "After we scored seventy on Clemson in the Orange Bowl, and Geno [Smith] and Tavon [Austin] and Stedman [Bailey] were all coming back, they were like, 'We're going to throw a lot of bombs. So should we do an air raid siren?' And there was discussion, and we said, 'You know, let's do it. Absolutely.'"27 Here Richard describes his team as launching an aerial assault on its opposing forces, bombing their defenses under the guidance of the school's veteran quarterback, Geno Smith. Further saturating WVU's football soundscape with martial signifiers, a student dressed as the school's mascot, the Mountaineer, prowls the sidelines during games wielding a long rifle loaded with blanks, which he fires into the air at key moments, including after scores and when he leads the team onto the field. Like their use of sirens, several other institutions across college football use mascots that carry firearms, including the Oklahoma State Cowboys, the Texas Tech Red Raiders, and the Tennessee Volunteers. These mascots incorporate their weapons into central moments of football's pageantry through acts such as hoisting their gun(s) in the air while leading their football team onto the field while the marching band plays their fight song or by shooting blanks into the air following touchdowns, which are also accompanied by similar musical fanfare. The additional sonic elements of sirens and gunfire equate the physical sacrifices of the players on the field with those of soldiers defending the often-stated ideal of "freedom," and this association is especially poignant, given 
that athletes enter the field of play immediately following the pregame period's nationalist tributes. In this way, athletes participate in an ongoing war ritual that reinforces violent constructions of masculinity that are prevalent in the US cultural mainstream.

Marching bands provide much of the interaction between music and the play-by-play action that occurs on the field. As is emphasized in the introduction to this article, marching bands are themselves martial signifiers. Band members wear uniforms, and they move in rank-and-file blocks and utilize traditional military commands such as "ten-hut" to signal a collective motion to a common physical position. Each institution in college football has one or more "fight songs" with unique lyrics that are traditionally played by their marching band. These tunes follow similar formats and themes, which almost always include references to battle, victory, and physical power. Fight songs are frequently implemented during football games as a means of celebrating specific developments, such as scoring plays on offense or forcing a turnover on defense. In this way, fight songs celebrate athletic accomplishments in the game while also urging the athletes to continue their battle for the remainder of the trial.

In addition to playing fight songs, marching bands frequently punctuate the game's action with a clear martial signifier: bugle calls. These take many forms, including not only the classic "charge" cheer but also numerous other variations. Similarly, Florida State University's (FSU) marching band performs a number of martial signifiers based on the school's association with the Seminole tribe, including its famous "War Chant," to which audience members move their arms vertically in a chopping motion (see Example 1). ${ }^{28}$ David Plack, FSU's director of athletic bands, described this particular selection's power to influence a game by referencing a situation from the 2012 football season when FSU found itself down two scores to Clemson University:

The Marching Chiefs single-handedly turned that stadium around, and the team fed off the "War Chant." The "War Chant" just kept pumping away, as it always does, and the crowd fed off us. The team fed off us. The crowd fed the team. Everything just kind of came around, and I think it's very easy to say that if you don't have a college marching band, would those types of turn-of-events and

Example 1. Florida State University's “War Chant." (Arrows represent audience members' downward chopping motions.)

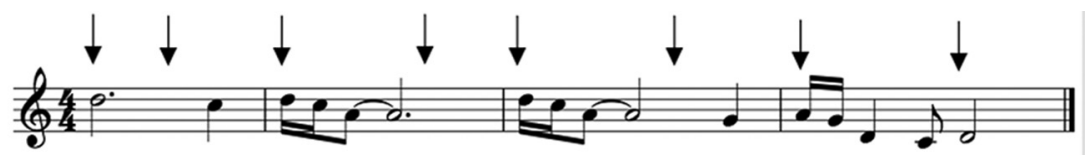


switching happen? And I'm not so sure they would. I think there's even some pretty good evidence to say, absolutely, the college band can have great effect on what's happening on the field. ... If you don't have something playing that "War Chant," I don't know what the fans are doing at that point, and I think the team's the same way: that they hear that, and I think it just drives them. I mean, I do. ${ }^{29}$

For Plack, the band's performance of this specific selection fueled the team competing on the field by unifying the crowd and thus urging the players to overcome their opponent.

Aside from the above descriptions of warsound via direct references to militaristic sound, college football's soundscape also draws heavily from cinematic representations of warrior masculinity, particularly within marching band repertoires. These selections are drawn from films that depict violent action, whether in the past, the future, or a fantasy. Table 3 outlines the eight cinematic themes that were performed by marching bands at multiple universities in this study. ${ }^{30}$ All of these selections are associated with strength, mostly violent strength, whether it is the single soldier battling an evil ruler in Gladiator, the warring families in Game of Thrones, or the man-eating shark of Jaws. Indeed, it seems that this quality, violence, may be the only common thread between each of these selections, as some either have amoral associations, as is the case with the Game of Thrones theme, which is not connected with any particular character from the show, or are outright villainous, such as "The Imperial March" associated with the evil Darth Vader from Star Wars.

Table 3. Cinematic/Television Themes Encountered at Multiple Universities

\begin{tabular}{|c|c|c|}
\hline Composer/Performer & Film/Show & Institutions \\
\hline The Immortals & $\begin{array}{l}\text { "Techno Syndrome” from } \\
\text { Mortal Kombat (1995) }\end{array}$ & GT, Miami, PUR, UK \\
\hline Ramin Djawadi & $\begin{array}{l}\text { Theme to Game of Thrones } \\
(2011-)\end{array}$ & Miami, FSU \\
\hline Claude-Michel Schönberg & $\begin{array}{l}\text { “Look Down” from } \\
\text { Les Misérables (2012) }\end{array}$ & $\begin{array}{l}\mathrm{UT} \text { (performed by } \\
\text { visiting band-OKST), } \\
\text { UK }\end{array}$ \\
\hline Walter Schumann & Theme to Dragnet (1949-59) & UF, WVU \\
\hline Leo Schifrin & $\begin{array}{l}\text { Theme to Mission: Impossible } \\
\text { (1966-73) }\end{array}$ & WVU, UCLA \\
\hline John Williams & $\begin{array}{l}\text { "Imperial March" from } \\
\text { Star Wars (1977) }\end{array}$ & $\begin{array}{l}\text { Miami, WVU, USC, } \\
\text { BU, PUR }\end{array}$ \\
\hline John Williams & Theme to Jaws (1975) & UF, WVU, IU, PUR \\
\hline Hans Zimmer & Theme to Gladiator (2000) & Miami, UO \\
\hline
\end{tabular}




\section{Time-Out: A Case Study in Cinematic Associations}

As a means of illustrating the extent to which cinematic associationssuch as representations of heroism and violence-are sonically projected onto football games, I offer the following brief account of a series of three plays and their accompanying musical context from IU's game against the University of Minnesota on November 2, 2013. Early in the game, Minnesota's offense took to the field already holding a lead by a score of seven to three over the Hoosiers of IU. The Hoosier defense needed to stop Minnesota's offense on three consecutive plays in order to regain possession of the football and, hopefully, gain some momentum in the game. As Minnesota's offense took the field, the IU band performed an arrangement of Nino Rota's theme from the Mafia tale The Godfather (1972), suggesting that there would be dire consequences for crossing the IU "family." After IU successfully stopped Minnesota's first play, the IU band performed an arrangement of John Williams's "Dual of the Fates" from Star Wars: The Phantom Menace (1999). In the original film, this musical theme accompanies the climactic showdown between the good Jedi knights and the evil Darth Maul. The band's performance here reinforced the message of the first selection while also signaling the importance of the upcoming play: a duel between opposing forces that could dramatically impact the outcome of the game. Minnesota managed only an incomplete pass on its subsequent play, meaning the team would have one final opportunity to extend its possession, or it would have to cede control of the football to the IU offense. As Minnesota prepared to run its subsequent play the IU band sounded another arrangement of a John Williams composition, the theme from shark-attack film Jaws (1975). Preceding Minnesota's final opportunity to extend its drive, this musical selection implied the team's imminent and ruthless elimination at the hands of IU's man-eating defense. Minnesota's play would indeed fail to gain the necessary yardage to extend its drive, and it would return the ball to the IU offense as the band performed the school's fight song, "Indiana, Our Indiana."

\section{Time-In: Resuming “Tough!”-Building Masculinity through Trial}

The selections described in the account above are representative of three very different types of films - a Mafia drama, a science fiction epic, and a shark-attack thriller, respectively-but they do share one common element that also situates each as being appropriate for implementation into college football's soundscape: the threat of violence. ${ }^{31}$ Additionally, as is the case with the sirens, gunshots, fight songs, and bugle calls described above, these cinematic selections are woven into the game on 
a play-by-play basis, informing the game's violent action on the fly and reinforcing its message of masculine power. Of course, some universities draw musical selections directly from cinema at a higher rate than others, but each marching band represented in this study drew at least some portion of its repertoire from movie soundtracks, and it seems that in most cases a piece must reinforce this core message at some level in order to be a candidate for inclusion in football's soundscape.

Musical selections sounded over PA systems also contribute to the experience of warsound. Ken McLeod describes the popular music accompanying football as consisting largely of "white-dominated hard rock, heavy metal, and country music - in addition to marching bands." 32 This study certainly affirms McLeod's first two listed genres, but the use of country music is not nearly as ubiquitous as rock and heavy metal. While these styles of music may not be as directly militaristic as the examples of warsound described above, they do engage with the game's trial stage through their various references to strength and power, which occur both musically and stylistically. In his consideration of heavy metal, Robert Walser cites a multitude of ways in which heavy metal bands "evoke power and intensity," including choosing names that allude to power (AC/DC), danger (Scorpions), or dangerous objects (Iron Maiden), as well as by their extensive use of power chords, which Walser points to as the "one feature that underpins the coherence of heavy metal as a genre." 33 This chord, an open fourth or fifth typically performed on a heavily amplified and distorted electric guitar, is also shared by much of the music categorized as hard rock. ${ }^{34}$ Because of this music's powerful and intense qualities, musical agents readily include it in the soundscape of a football game to the extent that the UO marching band director, Eric Wiltshire, described the atmosphere inside UO's stadium as a "heavy metal' vibe." 35 While UO may be more explicit in its affiliation with these types of music, this connection is certainly not unique to UO's games. This study found numerous examples of heavy metal / hard rock selections at virtually every institution sampled. Baylor University provides one such example, as its band played Guns N' Roses' "Welcome to the Jungle" and AC/DC's "Back in Black" repeatedly in the game against Oklahoma University in November 2013. That these sonic practices are even pervasive at Baylor-a private, conservative, Protestant university that one would expect to reject musical styles associated with blasphemous behavior and mysticism-demonstrates that heavy metal and football are inextricably linked. ${ }^{36}$ If Baylor is going to participate in bigtime college football, it is expected to participate in it sonically as well, which requires drawing upon these musical styles that "evoke power and intensity." 37

It is worth noting that warsound works in two ways. A number of authors have produced recent scholarship on music and modern war, 
and there is striking overlap between the musical styles preferred in football stadiums and those preferred in battle. In her analysis of American troops' personal music devices during the Iraq War, Lisa Gilman notes that while individual soldiers' playlists were surprisingly diverse, "heavy metal and hardcore rap genres were pervasive." 38 These same genres were easily the most preferred among football stadiums. Table 4 outlines the most frequently utilized performers or performing groups and their corresponding genre of performance from all the stadiums included in this study. ${ }^{39}$ It demonstrates that metal and hard rock are the most dominant commercial musical styles within college football stadiums, with rap maintaining a clear position behind these genres. The Isley Brothers are the sole nonmetal, nonrap representative on the list, thanks to the enduring popularity of their song "Shout" (1959). ${ }^{40}$

J. Martin Daughtry found trends similar to those found by Gilman in his analysis of a soldier's playlist for battle, which was published on Colby Buzzell's personal blog, "My War: Killing Time in Iraq" (see table 5). For Daughtry, this playlist reflects the "complex dialectical tension between the semantic field of the lyrics and performative elements such as prosody, timbre, instrumentation, and accent in many of the songs on this list." Some selections, such as REM's "Shiny Happy People," represent a certain "ironic distanciation" that was "likely one of Buzzell's tactics for staying sane during his tour of duty." One could make a similar

Table 4. Most Frequently Encountered Performers in Stadiums: Genre

\begin{tabular}{|c|c|c|c|}
\hline Performer & Genre & Stadiums & Institutions \\
\hline White Stripes & Rock & 11 & $\begin{array}{l}\text { GT, Miami, OSU, WVU, MICH, USC, } \\
\text { UO, IU, UT, PUR, UK }\end{array}$ \\
\hline Kernkraft 400 & Metal & 10 & $\begin{array}{l}\text { GT, Miami, FSU, WVU, USC, STAN, } \\
\text { UO, UM, PUR, UK }\end{array}$ \\
\hline Fall Out Boy & Rock & 8 & GT, FSU, WVU, USC, UO, IU, PUR, UK \\
\hline $\mathrm{AC} / \mathrm{DC}$ & Metal & 8 & $\begin{array}{l}\text { Miami, OSU, WVU, MICH, STAN, BU, } \\
\text { PUR, UK }\end{array}$ \\
\hline $\begin{array}{l}\text { Macklemore and Ryan } \\
\text { Lewis }\end{array}$ & Rap & 8 & $\begin{array}{l}\text { Miami, FSU, OSU, WVU, IU, BU, PUR, } \\
\text { UK }\end{array}$ \\
\hline Kanye West & Rap & 7 & Miami, USC, UO, BU, A\&M, PUR, UK \\
\hline $\begin{array}{l}\text { Ozzy Osbourne / Black } \\
\text { Sabbath }\end{array}$ & Metal & 6 & WVU, MICH, UCLA, IU, PUR, UK \\
\hline Guns N' Roses & Metal & 5 & Miami, UCLA, IU, BU, PUR \\
\hline Led Zeppelin & Rock & 5 & Miami, MICH, BU, UT, UK \\
\hline Metallica & Metal & 5 & Miami, UCLA, IU, PUR, UK \\
\hline Eminem & Rap & 5 & WVU, MICH, USC, IU, PUR \\
\hline Lil Jon & Rap & 5 & Miami, MICH, IU, UT, PUR \\
\hline Isley Brothers & $R \& B$ & 5 & MICH, USC, UO, PUR \\
\hline
\end{tabular}


Table 5. Colby Buzzell's "Soundtrack to Violance [sic]"

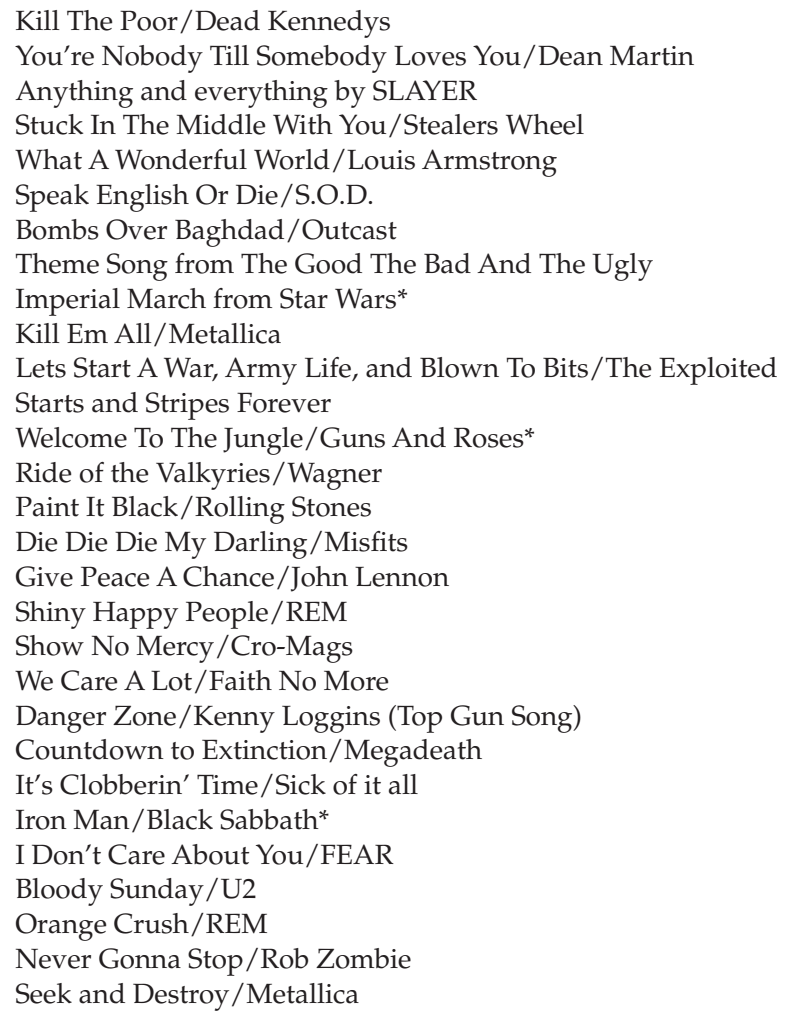

Note: The asterisks indicate selections that were also encountered in one or more of the sixteen games included in this study. Source: Colby Buzzell's personal blog, "My War: Killing Time in Iraq," quoted in J. Martin Daughtry, Listening to War: Sound, Music, Trauma, and Survival in Wartime Iraq (New York: Oxford University Press, 2015), 231.

case for the national popularity in football stadiums of the Isley Brothers' "Shout," which may offer a distraction from football's violence with its message of childlike love and danceable groove. ${ }^{41}$ Other selections on Buzzell's playlist carry certain "sonic icon[s] for aggression," such as the "crushing power chords" of Black Sabbath's "Iron Man." ${ }^{42}$ This selection is, of course, shared between the soundscapes of both football and war, but Daughtry's description of its "crushing power chords" could easily be applied to most of the music produced by the metal and rock performers included in table 4 .

Of course, music's meaning is connected to its context. In the case of soldiers tasked with performing violent acts, musical selections-whether 
inherently violent or not-carry unique meaning into this setting. Jonathan Pieslak explains that for soldiers,

their combat environment seems to largely influence how they interpret meaning in metal and rap. The songs chosen as an inspiration for combat appear to lend themselves, through timbre, performance, text, or some musical feature, to an understanding of meaning that relates to the experiences of combat or violence.... In this way, some soldiers connect the music to aspects of their surrounding environment, which involves combat. The social interpretation of metal and rap is constructed such that aspects of these genres "articulate" or reinforce soldiers' feelings and experiences of combat and violence. ${ }^{43}$

The same is true in the less so but still violent setting of a football game. Music that works in this sport largely does so because it maps easily onto the experiences of those in the stadium. Baylor University's use of the powerful, virtuosic guitar solo introduction to Guns N' Roses' "Welcome to the Jungle" fuels a crowd cheering for a defensive stop. The same can be said of Kanye West's "Power," Black Sabbath's "Iron Man," and Eminem's "Lose Yourself." These selections are very different in style and in content, but they are applicable in these situations because of their shared context.

In sum, the music accompanying the trial stage of a college football game, including all of the actual game, is an important component of football's projected masculinity. By appropriating instances of warsound through sounds adapted from, for, or with war, college football reinforces the ideal male form as being forged through trial, with players' bodies tried and broken as they progress through a crucial stage in the process of making a man. But the end of the game, and thus the trial stage, is not the end of the process of masculine framing. Smith's next stage reinforces the value of the first two stages by demonstrating (or creating) the ultimate glory that the trial ensures: the triumph of the male not in spite of but because of his physical tribulation.

\section{"Real Stuff!"-Moral and Cultural Triumph}

The period following a football game's conclusion is a time of reflection, camaraderie, and celebration. Here the game's focus shifts from the trials of the game to a larger framework of understanding that includes the team's history; the personal experiences of players, coaches, and fans; and the sport's cultural significance. Michael Oriard alludes to this framework when he writes of football's "romantic possibility": "It is not simply violence that spectators . . celebrate in football, but the human capacity to withstand violence and create something beautiful despite it, 
or even from it." ${ }^{44}$ Oriard's description is fully realized in the postgame period, Smith's final stage of masculine projection, as coaches and players greet each other in the middle of the field, put the physical contest behind them, and congratulate each other on a game well played. Many times, this moment is followed by players gathering for other displays of masculine camaraderie, whether by kneeling together for a prayer or by standing arm in arm to sing their school's fight song or alma mater. Such displays symbolize the moral development that the game's violence supposedly enables: opposing teams demonstrate their mutual respect for each other and demonstrate their selfless affinity for their teammates as they stand together as a single unit. These displays engender the value of such violent trials. As is the case with Smith's analysis of Eastwood's westerns, players' masculinity is established through the presentation and trial of their physical form, allowing the cultivation of these masculine qualities.

There are a number of sonic cues that accompany this period and reinforce its role in representing the triumph of football's romantic possibility. The band's performance of its institution's alma mater is perhaps the sonic moment that most distinguishes this stage from the previous two. With the game's violent moments completed, players and audience members are invited to participate in the performance of these slowertempo tunes, which are frequently structured as four-part chorales. These selections differ sharply from the up-tempo fight songs and commercial music that saturates the game's previous stages. This moment acts as a closing hymn, reinforcing the doctrine of an institution's supporters. WVU's alma mater offers one such example, and its lyrics position the events of the game within the larger cultural framework of the institution's history:

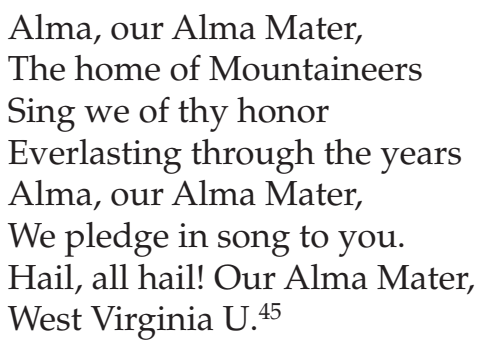

Following the game's physical trials, similar songs situate the events of the day as small parts of a larger, honorable, everlasting organization that includes more not only athletes but also all who identify as Mountaineers. The ultimate "triumph" is one's inclusion as a part of this history. Other institutions achieve the same effect by playing noninstitution-specific selections that are appropriated for these purposes, such as performances of Stephen Foster's "My Old Kentucky Home" at 
UK and the University of Louisville. In both cases, audience members sing the tune's nostalgic lyrics as a means of signifying the institution with which they are affiliated, similarly positioning their games in a larger framework of cultural significance:

The sun shines bright on the old Kentucky home.

'Tis summer, the people are gay;

The corn top's ripe and the meadow's in the bloom,

While the birds make music all the day;

The young folks roll on the little cabin floor,

All merry, all happy, and bright;

By ' $n$ by hard times comes a-knocking at the door,

Then my old Kentucky home, good-night!

Weep no more my lady,

Oh weep no more today!

We will sing one song for the old Kentucky home,

For the old Kentucky home far a-way! ${ }^{46}$

Regardless of whether universities use musical selections that are unique to their institution or are appropriated from other origins, their selections typically share a number of qualities: slow tempos, simple melodies that easily allow for communal singing, and nostalgic lyrics that provide a larger cultural context. These traits allow for maximum participation in these rituals as players and audience members alike are invited to celebrate their institution's history, as well as the cultural values that football espouses.

Beyond the singing of the alma mater, the postgame period's tone is dramatically affected by the outcome of the game: a last-minute victory comes with a considerably larger dose of celebration than a last-minute defeat, and victories or defeats by a large margin each carry their own distinctions, as lopsided games frequently lead to dwindling audience numbers before a game's conclusion. Among this project's case studies, at least four institutions' postgame rituals included additional celebratory musical selections beyond what is described above. Following wins at the University of Southern California, the football team gathers around the marching band, and one of the athletes leads the band in a performance of "Conquest," one of the school's songs, using a sword as a conducting baton. ${ }^{47}$ At WVU football games the sound operator only plays John Denver's "Country Roads" through the PA system in the case of a win. Richard explained that "Country Roads" is "a reward for a victory" that players do not earn after a loss. Richard continued, "If we lose, you shouldn't be celebrating and saying, 'Oh, what the heck, let's just sing "Country Roads."' Dang it, you lost." Stanford University's unofficial fight song is an arrangement of Free's "All Right Now" (1970), but its student-led band reserves a special arrangement of the tune exclusively 
for performance after wins. ${ }^{48}$ UT has performed a number of different selections following wins over the past several years, including an arrangement of DJ Khaled's “All I Do Is Win" (2010) in 2012 and Cameo's "Talkin' Out the Side of Your Neck" (1984) for the 2013 season. ${ }^{49}$ In each of these situations, these selections are used to bridge the second and third stages of the game, connecting the physical victory of the second stage to the larger context of the victory in the third.

Despite these institutional distinctions among postgame practices, the pageantry of this period fulfills the third and final of Smith's stages of masculinity, completing the celebration of the male physical form and its potential power. This process spans the pregame period's presentation of the male figure; the game period, in which the male figure is tested; and the postgame celebration of masculine strength, which is enabled via nostalgic celebration.

\section{Moving Forward}

In a 2013 interview, then US president Barack Obama revealed that on a personal level he could not ignore recent findings regarding the longterm consequences of football's violence, stating, "I would not let my son play football." ${ }^{\prime 50}$ Obama's comments were preceded by a multitude of publications on traumatic brain injuries resulting from playing football, including one study from earlier that year linking numerous manifestations of brain trauma, including depression and dementia, to the injuries sustained by professional football players. ${ }^{51}$ Later that year, the NFL settled a lawsuit filed by former players suffering from concussionrelated trauma, awarding them $\$ 765$ million..$^{52} \mathrm{New}$ studies continue to reveal more about the sport's inherent dangers, including a study conducted on recently deceased professional football players that found that eighty-seven of ninety-one former players suffered from chronic traumatic encephalopathy, a degenerative brain disease resulting from repetitive trauma to the head. ${ }^{53}$ Such findings have resulted in heightened concerns regarding football's safety at all levels of the sport.

Obama's brief statement on the matter signifies a great deal regarding the status of football in the United States. Obama rejected the longstanding association between football and American identity that George C. Marshall and John and Robert Kennedy so emphatically endorsed. Whereas football's lessons in strength and strategy were previously enough to warrant its esteemed position among American pastimes, the growing fears and concerns surrounding the modern game, and exemplified by Obama's comments, represent a potential cultural shift in which physical power and expressions of it are no longer perceived to be as valuable as holistic health, which includes emotional and mental components in addition to physical ones. Americans are pursuing longer, 
healthier lives instead of the stronger, more imposing power that football represents, while anxieties regarding football's violence have spread to all levels of the game. It appears that declining youth participation may be the first sign of decreasing popularity for the sport. ${ }^{54}$ These concerns threaten the profitability of the entire football industry, prompting rule revisions across all the sport's levels in an attempt to limit the types of player-to-player contact that may result in head trauma. Additionally, the NFL began providing grant funding to the National Institute of Health for further concussion research in late 2013, demonstrating that even at the sport's highest level its governing officials are taking steps to attempt to evolve the game, hoping that it will maintain its appeal as the world becomes more aware of the game's dangers. ${ }^{55}$

However, for those who prefer and defend traditional American constructions of masculine power, there is still significant resistance to reforming football culture, as is exemplified by the shift in rhetoric about the sport from the Obama administration to the Trump administration. Whereas Obama expressed concern about player safety and overall health, sitting US president Donald Trump attacked athletes who challenged football's construction of militarized masculinity. At a campaign rally in Huntsville, Alabama, on September 22, 2017, Trump stated, "Wouldn't you love to see one of these NFL owners, when somebody disrespects our flag, to say, 'get that son of a bitch off the field?"'"56 Trump doubled down on his rhetoric, tweeting several times the following day and suggesting that NFL players who do not stand for the flag should be fired. ${ }^{57}$ Trump's comments referred to a then year-old ongoing protest taking place during NFL pregame ceremonies started by quarterback Colin Kaepernick. During the 2016 preseason, reporters noticed that Kaepernick was opting not to stand during the pregame national anthem. When asked about his reasoning for this (in)action, Kaepernick stated, "I am not going to stand up to show pride in a flag for a country that oppresses black people and people of color... To me, this is bigger than football and it would be selfish on my part to look the other way. There are bodies in the street and people getting paid leave and getting away with murder." ${ }^{\prime \prime 8}$ Kaepernick's explanation connected his protest to the growing Black Lives Matter movement, which developed in protest of numerous black victims of police violence and systematic injustice. ${ }^{59}$ Weeks after Kaepernick began sitting, he shifted his method of protest to kneeling during the anthem after receiving guidance from former NFL player and retired Green Beret Nate Boyer, who suggested that kneeling would be a more respectful posture toward the military and veterans. Kaepernick took Boyer's advice, and dozens of athletes around the NFL joined the protests by similarly taking a knee during the anthem. ${ }^{60}$ These players' rationale for kneeling as a means of honoring the military was inadequate for Trump, who accused them of still "disrespect[ing] our 
country, our flag, our anthem." ${ }^{\prime 61}$ In his 2017 Huntsville speech, Trump's critical commentary on football did not end with his comments about the anthem protests but continued as a lamentation about the loss of the glory days of football. Trump maintained that NFL's television ratings were down in large part because of the decrease in violence resulting from an increase in penalties for illegal tackles. Trump explained, "You know today if you hit too hard-fifteen yards. Throw him out of the game. They had that last week. I watched for a couple of minutes. Two guys, just really beautiful tackle. Boom, fifteen yards! The referee gets on television. His wife is sitting at home; she's so proud of him. They're ruining the game. They're ruining the game. That's what they want to do. They want to hit. It is hurting the game." ${ }^{\prime 2}$ For Trump, both the anthem protests and the decrease in football's violence are connected reasons that the sport is decreasing in popularity and moving away from what Trump maintains is respectable American culture. To him, militarized masculinity is American masculinity; hence, he finds any aberration to football's alignment of violent action and patriotism to be inherently disrespectful. ${ }^{63}$

The cases of Obama and Trump make it clear that football is a nexus of the culture war currently playing out in American society and politics. While college football has largely avoided being pulled into the anthem controversy by virtue of the fact that college players are not typically on the field during the national anthem, the sport's soundscape resists any shift away from idealized expressions of violent strength and instead actively reinforces the construction of masculinity endorsed by George C. Marshall and the Kennedy brothers: a manliness centered on physical power and violent expression. This Trumpian brand of masculinity is expressed on the stage of a football field, as players are displayed, broken, and then celebrated, and these messages are reinforced via the sport's warsound-laced soundscape. So while scientific research has prompted the sport's various organizing bodies to make rule changes to lessen the game's violence in the name of safety, this humanistic consideration of college football's culture reveals that the sport is miles away from fundamental change, still defining a man's "Real Stuff!" as being "Rough!" and "Tough!"

\section{NOTES}

This article is indebted to many people. Especial thanks to Ron Pen and Diana Hallman, who both read early drafts of this essay and offered useful suggestions for improvement. I also presented an early iteration of this essay at the Society for Ethnomusicology's Midwest chapter meeting at Lawrence University in 2014, and the feedback I received there was formative the article's ultimate direction. I also want to acknowledge the University of Kentucky's Graduate School, Friends of Music, and Keith MacAdam Endowment for 
American Music, all of which supported my fieldwork financially. Final thanks to this article's reviewers and to the American Music editor, Gayle Magee, for their invaluable critiques.

1. John A. Adams, Keepers of the Spirit: The Corps of Cadets at Texas A\&M University, 1876-2001 (College Station: Texas A\&M University Press, 2001), 115-16.

2. Ibid. According to Adams, the A\&M bandmaster, George Farleigh, set out to make a suitable arrangement of the song for wind band performance in 1921, seeking to "put into music the irresistible swing of the march song that can be easily transposed into 'jazz' time, when the occasion demands, that makes it appeal to the martial spirit at A. and M. College" (ibid., 115-16). Farleigh's efforts resulted in a catchy tune that suited both singing and marching, and it quickly became a favorite among the student body and alumni.

3. "The Eyes of Texas Are Upon You" is sung to the melody of "I've Been Working on the Railroad." For more on the history of the University of Texas at Austin's school song, see Jim Nicar, "The Origins of 'The Eyes of Texas,'" University of Texas, http://web.archive.org/ web/20160327234942/https:/ /lhb.music.utexas.edu/history/songs/ (accessed December $28,2015)$.

4. "Aggies" is a reference to the school's historical strength in agriculture programs.

5. "Hell" is absent from the original lyrics and is replaced with a series of nonsense syllables. "Hell" is implied via rhyme scheme through its pairing with the word "well."

6. Adams, Keepers of the Spirit, 63.

7. For additional background on the development of American wind bands, see Raoul Camus et al., "American Wind Bands," in Grove Music Online, ed. Keith Polk et al., Oxford University Press, http://web.archive.org/web/20180602045147/http://www .oxfordmusiconline.com/grovemusic/view/10.1093/gmo/9781561592630.001.0001/omo -9781561592630-e-0000040774 (accessed September 23, 2015).

8. This quote is now preserved on a bronze plaque, which members of the West Point football team touch before every game. See "Army West Point Team Traditions," Go Army West Point, http://web.archive.org/web/20170501040257/http://goarmywestpoint .com:80/sports/2015/7/14/gameday_0714155035.aspx (accessed April 1, 2014).

9. Robert Lipsyte, "Sports of the Times: Many Happy Returns," New York Times, September 29, 1969.

10. "Kennedy Will Appear on TV at Football Award Fete Dec. 5," New York Times, November 23, 1961.

11. Ken McLeod, "We Are the Champions": The Politics of Sports and Popular Music (Burlington, VT: Ashgate, 2011), 32-33.

12. Paul Smith, "Eastwood Bound," in Constructing Masculinity, ed. Maurice Berger, Brian Wallis, and Simon Watson (New York: Routledge, 1995), 77-97. Smith's theory is an extension of Paul Willemen's analysis of masculinity in Anthony Mann's westerns in "Looking at the Male," Framework, no. 15-17 (1981).

13. Smith, "Eastwood Bound," 81, 95.

14. Sue Curry Jansen, Critical Communication Theory: Power, Media, Gender, and Technology (Lanham, MD: Rowman \& Littlefield, 2002), 190-91.

15. Ibid.

16. For more on the activities included in this space, see my dissertation: John Michael McCluskey, "Music as Narrative in American College Football" (PhD diss., University of Kentucky, 2016).

17. Megan Robertson, interview by the author, October 25, 2013, University of Oregon. 18. Ibid.

19. Ultimately, West's "Stronger" is about gratification stemming from a delayed/ prolonged sexual encounter. However, the song's meaning is easily transformed in an athletic context. 
20. For more on expressions of power in heavy metal, see Robert Walser, Running with the Devil: Power, Gender, and Madness in Heavy Metal Music (Middletown, CT: Wesleyan University Press, 1993).

21. Cole's original lyric here is "Bitch I'm about to blow up," but Oregon's production team used an edited version of the song.

22. Ken McLeod, "Masculinity in African American Music and Sports," American Music 27, no. 2 (2009): 219-20.

23. I have written a more thorough examination of race and music in college football in McCluskey, "Music as Narrative."

24. Garrett, "Struggling to Define a Nation: American Music in the Twentieth Century" (PhD diss., University of California, Los Angeles, 2004).

25. "A Tradition of Spirit: Fight Song-Mighty Oregon," University of Oregon Athletics, http:/ / web.archive.org/web/20190122231021/https:/ /goducks.com/sports / 2005/7/12/153838.aspx (accessed January 4, 2016).

26. A fifth institution, the University of Miami, incorporated similar sirens to represent the school's mascot, the Hurricane. Regardless, in both the contexts described above and that of Miami, the sirens signify the damage that the home team will deal upon the visitors.

27. "Richard," interview by the author, West Virginia University. I have assigned this informant the alias "Richard" due to the sensitive nature of this source's comments in other areas of my research. This informant also references three WVU football players, all of whom went on to have NFL careers: Geno Smith (quarterback), Tavon Austin (wide receiver), and Stedman Bailey (wide receiver).

28. For video of this practice, see KENFL74, "FSU Seminoles College Football BCS National ChampionsTomahawk Chop at DOAK," YouTube, http://web.archive.org/ web/20190122231243/https:/ / www.youtube.com/watch?v=Nlgfs7bIhys (accessed February 19,2016 ).

29. David Plack, interview by the author, September 17, 2013, Florida State University.

30. "Techno Syndrome" predates the 1995 film, as it was released in 1993 to accompany the release of the video game Mortal Kombat. Similarly, the musical Les Misérables premiered onstage in Paris in 1980. The date specified above, 2012, represents the most recent cinematic adaptation of the musical, after which many of the production's more famous selections, including "Look Down," experienced a burst of popularity, likely contributing to the song's inclusion in these bands' repertoires.

31. Such selections also allude to the significant role of cinema in American culture as another form of entertainment that glorifies masculine violence and reinforces/defines the "norms" of American society. For more on the relationship between film and ultraviolence, see Stephen Prince, Screening Violence (New Brunswick, NJ: Rutgers University Press, 2000).

32. McLeod, We Are the Champions, 137.

33. Walser, Running with the Devil, 2.

34. For further discussion of the complex network of sonic qualities that construct heavy metal, see Walser, "Beyond the Vocals: Toward the Analysis of Popular Musical Discourses," in ibid.

35. Eric Wiltshire, interview by the author, October 25, 2013, University of Oregon.

36. Additionally, Christian heavy metal bands further complicate the fluidity of sonic meaning in the context of this genre, though they do not seem to be a part of college football's musical repertoires. For more information, see Eric Strother, "Unlocking the Paradox of Christian Metal Music" (PhD diss., University of Kentucky, 2013).

37. Baylor does self-impose some limitations on the music it includes in its football playlists, exclusively governed by limitations on lyrical content. John Garrison, Baylor's associate athletic director for marketing, explained, "No sex, no drinking, no sex, no smoking, no drugs, stuff like that." Otherwise, "we're not resistant to playing a certain band or group because of maybe what they stand for unless there's some extremes." Garrison also 
explained that in some cases an instrumental track can stand in for a selection that does not qualify for in-stadium performance: "Now, we do play a lot of those instrumental-type stuff from a rap or hip-hop standpoint" (John Garrison, interview by the author, November 13, 2013, Baylor University).

38. Lisa Gilman, "An American Soldier's iPod: Layers of Identity and Situated Listening in Iraq," Music and Politics 4, no. 2 (2010), http:/ / web.archive.org/web/20180603185445/ https:/ / quod.lib.umich.edu/m/mp/9460447.0004.201?view=text;rgn=main (accessed April 3, 2013). Gilman notes that it is important to recognize the diversity of musical preferences in addition to heavy metal and rap, as "an eclectic mix of musical styles and artists also indicates the multiple identities of individuals in addition to the many different functions that music plays in the moment-to-moment experience of deployment."

39. These data include both music sounded over PA systems and arrangements performed by marching bands.

40. The Isley Brothers' hit selection serves as an effective communal activity for large crowds because of its familiar dance moves. Notably, the song's gestural responses include raising one's hands into the air on the word "shout" and physically mimicking the song's dynamics by gradually crouching during "a little bit softer now" and then gradually standing upright during "a little bit louder now."

41. The most likely reason that "Shout" became a popular stadium anthem is the song's prominent association with university Greek life as established by the film Animal House (1978). However, given that the film is now forty years old, it is difficult to gauge how present this association is in the audience members' minds.

42. J. Martin Daughtry, Listening to War: Sound, Music, Trauma, and Survival in Wartime Iraq (New York: Oxford University Press, 2015), 232.

43. Jonathan Pieslak, Sound Targets: American Soldiers and Music in the Iraq War (Bloomington: Indiana University Press, 2009), 147.

44. Michael Oriard, Reading Football: How the Popular Press Created an American Spectacle (Chapel Hill: University of North Carolina Press, 2007).

45. To hear a performance of this selection, see goxybr, "West Virginia Alma Mater," YouTube, https://web.archive.org/web/20190123000434/https://www.youtube.com/ watch?v=M0x7SnQXSx0 (accessed January 9, 2016).

46. Lyrics from "Kentucky Songs," University of Kentucky Alumni Association, https:/ / web.archive.org/web/20141228022036/http:/ / www.ukalumni.net/s/1052/semi-blank -noimg.aspx?pgid=365\&gid=1 (accessed January 22, 2019). Both the University of Kentucky and the University of Louisville adapted Foster's original lyrics to remove explicit references to race, notably including Foster's original line, "Tis summer, the darkies are gay." To hear a joint performance from these two institutions in a pregame context, see Philflash, "My Old Kentucky Home Performed Jointly by UK and U of L," YouTube, http:/ / web .archive.org/web/20190122232207/https:/ /www.youtube.com/watch?v=Xwk7ACZNKi0 (accessed January 9, 2016). To review the song with Foster's original lyrics, see Stephen Foster, "My Old Kentucky Home, Good-Night," Philadelphia Current (Philadelphia, n.d.), IMSLP, http:/ / web.archive.org/web/20190122232110/http://conquest.imslp.info/ files/imglnks/usimg/a/ad/IMSLP257333-PMLP307841-My_Old_Kentucky_Home,_ Goodnight.pdf (accessed January 22, 2019).

47. Arthur Bartner, interview by the author, October 9, 2013, University of Southern California.

48. Ellen Kettler, interview by the author, October 18, 2013, Stanford University.

49. Anthony Marinello, interview by the author, November 14, 2013, University of Texas at Austin.

50. David Remnick, "Going the Distance: On and Off the Road with Barack Obama," New Yorker, January 27, 2014, http:/ /web.archive.org/web/20190112023545/https:/ / www .newyorker.com/magazine/2014/01/27/going-the-distance-david-remnick (accessed 
April 1, 2014). Obama was speaking figuratively in this instance, as he has two daughters and no sons.

51. Gary W. Small et al., "PET Scanning of Brain Tau in Retired National Football Players: Preliminary Findings," American Journal of Geriatric Psychiatry 21, no. 2 (2013).

52. Ken Belson, "NFL Agrees to Settle Concussion Suit for $\$ 765$ Million," New York Times, August 30, 2013, http://web.archive.org/web/20181123114506/https://www.nytimes .com/2013/08/30/sports/football/judge-announces-settlement-in-nfl-concussion-suit .html (accessed January 10, 2016). That figure has since increased, as the presiding judge expressed concerns that the initial sum might not be adequate to cover all the potential cases. See "Judge Approves Potential \$1 Billion Settlement to Resolve NFL Concussion Lawsuits," USA Today, April 22, 2015, http:/ / web.archive.org/web/20181011024018/https:/ / www.usatoday.com/story/sports/nfl/2015/04/22/nfl-concussion-lawsuit-settlement -judge-1-billion/26192827/ (accessed January 10, 2016).

53. Jason M. Breslow, "New: 87 Deceased NFL Players Test Positive for Brain Disease," PBS, September 18, 2015, http://web.archive.org/web/20181122205215/https://www .pbs.org/wgbh/frontline/article/new-87-deceased-nfl-players-test-positive-for-brain -disease/ (accessed January 10, 2016).

54. According to a report by the Wall Street Journal, football participation among six- to eighteen-year-olds fell 5.4 percent between 2008 and 2014. However, other major sports, including basketball and baseball, also saw decreases in participation. There is not enough evidence to effectively prove that the decrease in football participation is definitively linked to the increasing awareness of long-term concerns associated with head trauma. See Ryan Wallerson, "Youth Participation Weakens in Basketball, Football, Baseball, Soccer," Wall Street Journal, January 31, 2014, http:/ / web.archive.org/web/20161107091732/http:/ / www.wsj.com/news/articles/SB10001424052702303519404579350892629229918 (accessed January 10, 2016).

55. "NIH and NFL Tackle Concussion Research," National Institute of Neurological Disorders and Stroke, http://web.archive.org/web/20181023042351/https://www.nih .gov/news-events/news-releases/nih-nfl-tackle-concussion-research (accessed April 1, 2014).

56. "President Trump Remarks at Senator Strange Campaign Rally," C-SPAN, September 22, 2017, http:/ / web.archive.org/web/20181215073027/https:/ /www.c-span.org/ video/?434480-1/president-trump-campaigns-alabama-senator-luther-strange (accessed March 26, 2018).

57. For a summary of Trump's Twitter commentary following the Huntsville rally, see Marissa Payne, "NFL Owners, Team Presidents and Chief Executives React to President Trump's Comments," Washington Post, September 24, 2017, http://web.archive. org/web/20190113145516/https:/ / www.washingtonpost.com/news/early-lead/wp/ 2017/09/24/nfl-owners-team-presidents-and-chief-executives-react-to-president-trumps -comments / (accessed April 2, 2016).

58. Steve Wyche, "Colin Kaepernick Explains Why He Sat during National Anthem," NFL, August 27, 2016, http://web.archive.org/web/20190122233828/http://www.nfl .com/news/story/0ap3000000691077/article/colin-kaepernick-explains-why-he-sat -during-national-anthem (accessed April 4, 2016).

59. For a more in-depth consideration of music/sound in the context of the Black Lives Matter movement, particularly regarding weaponized sound, see William Cheng, "Coda: 'If We Break,'" in Just Vibrations: The Purpose of Sounding Good (Ann Arbor: University of Michigan Press, 2016), 95-103.

60. One of the first athletes to join Kaepernick was his teammate Eric Reid, who penned this editorial about his rationale in the days following Trump's Huntsville commentary: "Eric Reid: Why Colin Kaepernick and I Decided to Take a Knee," New York Times, September 25, 2017, http:/ /web.archive.org/web/20170925183413/https:/ /www.nytimes 
.com/2017/09/25/opinion/colin-kaepernick-football-protests.html (accessed April 2, 2018).

61. "Trump to Hannity: NFL Players 'Cannot Disrespect Our Country, Our Flag, or Our Anthem,'” Fox News Insider, October 11, 2017, http:/ / web.archive.org/web / 20190105164611/http: / /insider.foxnews.com/2017/10/11/trump-sits-down-hannity -9pm-et-nfl-cannot-disrespect-our-country (accessed April 3, 2018).

62. "President Trump Remarks."

63. Clearly the NFL team owners are worried that the protests are causing ratings issues, as Trump suggests. Colin Kaepernick has gone unsigned and unemployed as a quarterback for over a year, despite outstanding ability, exemplified by his leading the San Francisco 49ers to the NFL championship game, the Super Bowl, in 2012. Similarly, fellow anthem protester and safety Eric Reid remained unsigned as a free agent throughout the entire 2018 offseason, which he maintained was directly related to his protests. After the 2018 season began, Reid was signed to play for the Carolina Panthers, though during the season he argued that the NFL targeted him with a disproportionate amount of drug testing as likely retaliation for his protests. See Nick Wagoner, "Eric Reid Says Owners Haven't Signed Him Because of Protests," ESPN, March 16, 2018, http:/ / web .archive.org/web/20180505054625/http://www.espn.com/nfl/story/_/id/22783800/ free-agent-safety-eric-reid-says-protests-national-anthem-keeping-finding-new-team (accessed April 3, 2018). See also Dan Graziano, “The Targeting of Eric Reid: Where's He's Probably Wrong, and Dead Right," ESPN, November 29, 2018, http:/ / web.archive.org/ web/20181130123207/http://www.espn.com/nfl/story/_/id/25407914/the-targeting -eric-reid-where-probably-wrong-dead-right (accessed January 22, 2019). 